\title{
NT pro- B-type Natriuretic Peptide in the Small Ventricular Septal Defect in Children
}

\author{
Rahmat Budi Kuswiyanto $^{1} \mathbb{D}$, Putria Apandi ${ }^{*} \mathbb{D}$, Dany Hilmanto ${ }^{1} \mathbb{D}$, Muhammad Hasan Bashari ${ }^{2}$, Sri Rahayuningsih ${ }^{1} \mathbb{D}$ \\ ${ }^{1}$ Department of Pediatric and Child Health, Hasan Sadikin Hospital, Universitas Padjajaran, Indonesia; ${ }^{2}$ Department of \\ Pharmacology and Therapy Faculty of Medicine Universitas Padjajaran, Indonesia
}

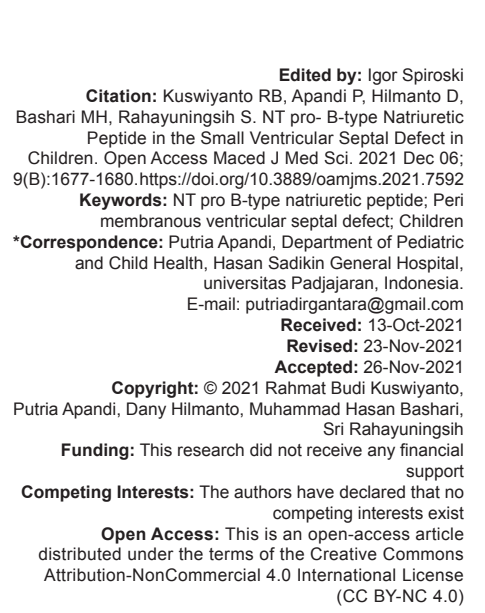

Introduction

Brain natriuretic peptide is a cardiac hormone secreted from the left ventricular myocardium due to ventricular expansion and volume overload. It is synthesized as a preprohormone containing 108 amino acids processing releases the biologically active-32 amino acids peptide and an $\mathrm{N}$-terminal pro-brain natriuretic peptide [1].

A recent study shows that small ventricular septal defect (VSD) will impact adulthood, the complications such as endocarditis, congestive heart failure, aortic regurgitation, arrhythmia, and ventricular dysfunction [2], [3], [4]. Nevertheless, data on plasma B-type natriuretic peptide (BNP) are still scarce, particularly in small peri membranous VSD (pmVSD). Thus, the purpose of this study was to determine plasma BNP levels in children before and after transcatheter closure of a small pmVSD.
Patients and Methods

The Medical Research Ethics Committee approved this ethical clearance of Dr. Hasan Sadikin General Hospital Bandung, Indonesia. A pretest-posttest design was conducted on pmVSD patients before and after transcatheter closure of pmVSD. The inclusion criteria for the subject were patients with small pmVSD as measured using echocardiography and angiography, those under 18 years old, and QP/QS $<1.5$. Small pmVSD in this study was defined as a VSD with a size of less than one-third of the aorta diameter annulus. Prior to the procedure, echocardiography was done to evaluate LV dimension using m-mode echocardiography. One month after the procedure, we also observed the valve regurgitation, particularly aortic regurgitation, device position, and residual shunt after the procedure. Echocardiography was performed using Philips epic 7 (Philips North American Corporation USA) echocardiography machine for 2D imaging. Thirty-two subjects participated in this study (minimum required sample size $=30$ ). 


\section{Clinical assessment}

All children underwent a clinical examination dan assessment, including a complete cardiac examination. The severity of HF was determined using the Modified Ross's Clinical Score for heart failure diagnosis. This score classified patients into No cardiac heart failure $(\mathrm{CHF})=0-2$ points, mild $\mathrm{CHF} 3-6$ points, moderate CHF 7-9 points, and severe CHF 10-12 points [5].

\section{Echocardiography assessment before percutaneous closure}

We assist VSD carefully before the procedure. VSD assessment was performed, which included: Site of VSD, size of the VSD from both sides of defect, and abnormality of the valve.

\section{Amino-terminal pro-brain natriuretic peptide measurements}

All blood samples for NT-pro BNP measurement were collected before the VSD closure procedure and 1 month after the procedure. Samples were collected in a tube and centrifuged for $10 \mathrm{~min}$ at $3000 \mathrm{rpm}$. Serum was extracted and stores in $-80^{\circ} \mathrm{C}$ until the analysis day. ELISA techniques determined the plasma concentration of NT-pro BNP in the plasma. (Elabsience Biotechnology Inc).

\section{Follow-up}

After VSD device closure, all patients received tablet aspirin at a dose of 3-5 mg/kg/day for 6 months. On the day of discharge and 1 month after the procedure, a clinical examination, electrocardiography monitoring, and transthoracic echocardiography were conducted to determine the left ventricular end-diastolic diameter (LVEDD). One month after the procedure, pediatric cardiologists who are blind to the procedure will do transthoracic echocardiography, quantify m-mode, and evaluate valve regurgitation, device location, and residual shunt.

\section{Statistical analysis}

Statistical analysis was performed using the Statistical Package for Social Sciences for windows version 18.0. Analysis was performed using descriptive statistics, and all data were expressed as mean \pm standard deviation and $\%$ ratio. Numeric data with normal distribution were analyzed by paired t-test, and non-normal distribution data were analyzed by Wilcoxon test. $p<0.05$ was considered statistically significant.

\section{Results}

This study was conducted during the study period of July 2019 to December 2019. Percutaneous closure of VSDs was successfully performed in all patients. Subjects comprised 12 males and 20 females. All patients were asymptomatic, no symptoms occurred, and no one had a recurrent respiratory infection. Aortic regurgitation and prolapse of the right coronary cusp of the aorta were observed before the procedure in $6 \%$ and $12 \%$ of patients, respectively. After the procedure, the trivial aortic regurgitation was seen in 3 patients (9.3\%). No death or urgent cardiac surgery complication was seen during the study period, and no device embolization occurred. Furthermore, no atrioventricular block was observed on electrocardiography evaluation. One patient developed sinus bradycardia but normal in systolic and diastolic functions. Intra-device mild residual shunt remained in 12 patients. No hematoma occurred. There was no death, endocarditis, or devicerelated complication was seen during the follow-up.

The characteristic data is shown in Table 1. Almost all children who include in this study has normal weight and no heart failure observe. Table 2 shows that the heart function before and after intervention had no significance difference, but the NTproBNP and heart dimension show significance decreament.

\section{Discussion}

There are controversies about treatment for small VSD. Small, restrictive, and isolated VSDs with a small left to right shunt rarely develop pulmonary hypertension and have an excellent long-term prognosis [6], [7]. However, there is evidence of a long-term prognosis of LV dysfunction in adulthood, which may be a rationale for small VSD closure in childhood [8]. We hypothesized that there might be a chronical volume overload due to LVEDD dilatation, although the size of the VSD is small. Left ventricular dilatation is one of the complications of left ventricular volume overload caused by VSD.

Recent studies have shown that serum BNP level increases during different types of hemodynamic overload of the heart, including in VSD [9], [10]. The main stimulus for increased BNP and NT pro BNP synthesis and secretion is the myocardial wall stress. BNP and NT pro BNP are cardiac hormones produced from the myocardium of the left ventricle in response to ventricular pressure and/or volume overload [11], [12], [13]. However, the cut-off values of NT-pro BNP reference level in children have not been fully evaluated, a previous research conducted by $\mathrm{Kim}$ et al. show that even in normal children without cardiac disease the level 
Table 1: Subject characteristics

\begin{tabular}{ll}
\hline Variable & $\mathrm{n}=32$ \\
\hline Age (years) & \\
$\quad$ Mean \pm SD & $8.6 \pm 4.2$ \\
Sex, $\mathrm{n}(\%)$ & $12(37.5)$ \\
$\quad$ Boy & $20(62.5)$ \\
$\quad$ Girl & \\
Weight (kg) & $22.0(10.0-45.0)$ \\
$\quad$ Median (Min-Max) & \\
Height (cm) & $122(75-160)$ \\
$\quad$ Median (Min-Max) & \\
BMI/U & $31(94.0)$ \\
$\quad$ Norm weight (-2-2 SD) & $1(3.0)$ \\
$\quad$ Skinny (<-2SD) & $1(3.0)$ \\
$\quad$ Very thin (<-3SD) & $31(94.0)$ \\
Ross score, $\mathrm{n}(\%)$ & $1(3.0)$ \\
$\quad \quad$ & $1(3.0)$ \\
$\quad$ 1 & $1.18 \pm 0.14$ \\
$\quad$ Qp/Qs & \\
$\quad$ Mean \pm SD & $24: 49(09: 33-72: 09)$ \\
Fluoro time (mm: ss) & \\
$\quad$ Median (Min-Max) & $01: 20(00: 50-02: 50)$ \\
Procedure time (hh: mm) & \\
$\quad$ Median (Min-Max) & $3.39 \pm 0.71$ \\
Defect size at RV from TTE (mm) & \\
$\quad$ Mean \pm SD & $2.80 \pm 1.24$ \\
Defect size at RV from angiography (mm) & \\
$\quad$ Mean \pm SD & $2.59(0.97-7.78)$ \\
Distant to aortic valve from angiography (mm) & \\
$\quad$ Median (Min-Max) & \\
\hline RV: Right ventricle, LV: Left ventricle, TTE: Transthoracic echocardiography. & \\
$\quad$ &
\end{tabular}

of NT pro BNP were in range $6-35.000 \mathrm{pg} / \mathrm{ml}$, and in this study also show that in cardiac patient show higher level of NT-pro BNP compare with children without cardiac disease [14]. In this study, the NT pro-BNP levels 1 day before and 30 days after transcatheter closure of small pmVSD were evaluated, and a significant decrease of NT pro-BNP 30 days after small pmVSD closure by transcatheter was observed. This shows that even in small pmVSD, LV volume overload should be considered because it may lead to a hypervolemic situation. Hence, closing small pmVSD is considered advantageous.

Table 2: Heart dimension, function, and NT pro BNP level before and after the procedure

\begin{tabular}{lllll}
\hline Variable & $\mathrm{n}$ & \multicolumn{2}{l}{ Follow-up } & p-value \\
\cline { 3 - 4 } & & Month 0 & Month 1 & \\
\hline LVEDD $(\mathrm{mm})$ & 32 & $39.1 \pm 5.5$ & $37.5 \pm 5.8$ & $0.034^{\mathrm{a}^{\mathrm{a}}}$ \\
LVESD $(\mathrm{mm})$ & 32 & $24.7 \pm 4.0$ & $24.0 \pm 4.1$ & $0.259^{\mathrm{a}}$ \\
NT pro-BNP $(\mathrm{ng} / \mathrm{ml})$ & 32 & $1.08(0.74-3.47)$ & $0.91(0.68-2.07)$ & $<0.001^{\mathrm{b}_{*}}$ \\
MPI LV & 32 & $0.36 \pm 0.06$ & $0.33 \pm 0.08$ & $0.092^{\mathrm{a}}$ \\
LV mass index & 32 & $83.2 \pm 29.4$ & $85.8 \pm 20.6$ & $0.628^{\mathrm{a}}$ \\
EF (\%) & 32 & $66.8 \pm 6.0$ & $67.4 \pm 5.5$ & $0.688^{\mathrm{a}}$ \\
FS (\%) & 32 & $36.4 \pm 4.5$ & $37.1 \pm 4.4$ & $0.554^{\mathrm{a}}$ \\
LA/Ao & 32 & $1.30 \pm 0.24$ & $1.25 \pm 0.23$ & $0.381^{\mathrm{a}}$ \\
\hline LVEDD: Left ventricular end-diastolic diameter, EF: Ejection fraction, FS: Fractional shortening,
\end{tabular}

In this prospective follow-up study, the impacts of small pmVSD closure to LEVDD and NT pro BNP level 1 month after the procedure were evaluated. Small pmVSD is not usually seen with heart failure. In a cohort of 124 infants, the incidence of spontaneous closure was found to increase to $67 \%$ at 5 years of age [15]. Another study by Miyake et al. in Japan showed that spontaneous closure of pmVSD may occur at 6 years old or school age [16]. At present, there is no standard treatment for small VSDs [17]. There was no significant difference in heart function as measured by ejection fraction and FS, which is in line with the literature stating that systolic impairment typically occurs late [18], [19].

The findings of this study indicated that 1 month following percutaneous transcatheter closure of pmVSD, the LVEDD improved. This result differs from the study conducted by Ali et al. in Cairo that showed an insignificant decline in both LVEDD and left ventricular end-systolic diameter (LVESD) after 3 months of VSD closure [6]. The improvement of LVEDD after pmVSD closure might be due to the size of VSD. The size of pmVSD in this research was small VSD, different from the study conducted by Ali et al. which the size of VSDs was moderate [6]. Other complications observed were dysfunction of the left ventricle, arrhythmias, endocarditis, aortic regurgitation, and aortic valve prolapse [20], [21].

Nevertheless, this study has a limitation because it did not represent a total population. The study was only performed in two hospitals using different types of devices to close VSD, which may cause bias.

In the current study, there was no change in left ventricular ejection fraction (LVEF) after transcatheter closure, and this result was similar with Pawelec-Mojtalik et al. and Ali et al., who reported that the systolic function was not changed after VSD closure. This can be explained by the fact that patients who undergo VSD transcatheter closure mostly have small-sized restrictive defects, so the LVEF changes are subtle [6], [22].

\section{Conclusion}

Lower serum NT pro-BNP levels in small pmVSD may indicate that LV volume excess may occur, resulting in lung volume overload and later LV dysfunction. This finding provides a rationale for considering the closure of small pmVSDs in children.

\section{References}

1. Jacob J, Chopra S, Cherian D, Verghese P. Physiology and clinical significance of natriuretic hormones. Indian J Endocrinol Metab. 2013;17(1):83. https://doi.org/10.4103/2230-8210.107869 PMid:23776857

2. Otterstad J, Erikssen J, Michelsen S, Nitter-Hauge S. Longterm follow-up in isolated ventricular septal defect considered too small to warrant operation. J Intern Med. 1990;228(4):305-9. https://doi.org/10.1111/j.1365-2796.1990.tb00237.x

PMid:2266337

3. Kidd L, Driscoll D, Gersony W, Hayes C, Keane J, O'Fallon W, et al. Second natural history study of congenital heart defects. Results of treatment of patients with ventricular septal defects. Circulation. 1993;87 Suppl 2:I38-51. PMid:8425321

4. Neumayer U, Stone S, Somerville J. Small ventricular septal defects in adults. Eur Heart J. 1998;19(10):1573-82. https://doi. org/10.1053/euhj.1998.1083 PMid:9820997

5. Ross R, Bollinger R, Pinsky W. Grading the severity of congestive heart failure in infants. Pediatr Cardiol. 1992;13(2):72-5. https:// 
doi.org/10.1007/BF00798207

PMid:1614922

6. Ali Y, Hassan M, Fiky A. Assessment of left ventricular systolic function after VSD transcatheter device closure using speckle tracking echocardiography. Egypt Hear J. 2019;71(1):1. https:// doi.org/10.1186/s43044-019-0001-7

PMid:31659511

7. Gersony W, Hayes C, Driscoll D, Keane J, Kidd L, O'Fallon W, et al. Second natural history study of congenital heart defects. Quality of life of patients with aortic stenosis, pulmonary stenosis, or ventricular septal defect. Circulation. 1993;87 Suppl 2:152-65.

PMid:8425323

8. Karonis T, Scognamiglio G, Narayan S, Montanaro C, Uebing A, Diller $G$, et al. Clinical course and potential complications of small ventricular septal defects in adulthood: Late development of left ventricular dysfunction justifies lifelong care. Int J Cardiol. 2016;208:102-6. https://doi.org/10.1016/j. ijcard.2016.01.208

PMid:26844920

9. Kaya Y, Akdemir R, Gunduz H, Murat S, Bulut O, Kocayigit I, et al. Changes in serum natriuretic peptide levels after percutaneous closure of small to moderate ventricular septal defects. ScientificWorldJournal. 2012;2012:328697. https://doi. org/10.1100/2012/328697

\section{PMid:22629130}

10. Suda K, Matsumura M, Matsumoto $M$. Clinical implication of plasma natriuretic peptides in children with ventricular septal defect. Pediatr Int. 2003;45(3):249-54. https://doi. org/10.1046/j.1442-200x.2003.01716.x

PMid:12828576

11. Fernandes B, Maher K, Deshpande S. Cardiac biomarkers in pediatric heart disease: A state of art review. World $\mathrm{J}$ Cardiol. 2016;8(12):719-27. https://doi.org/10.4330/wjc.v8.i12.719 PMid:28070239

12. Farouk A, Alogwhary M, Hassan M, El-minshawy A. Circulating B-type natriuretic peptide levels and its correlation to $Q p / Q s$ ratio among children undergoing congenital heart surgeryNC-ND license. J Egypt Soc Card Surg. 2017;25:58-63. https:// doi.org/10.1016/j.jescts201

13. Weber M, Hamm C. Role of B-type natriuretic peptide (BNP) and NT-proBNP in clinical routine. Heart. 2006;92(6):843-9. https://doi.org/10.1136/hrt.2005.071233 PMid:16698841

14. Kim HS, Choi HJ. N-terminal pro-B-type natriuretic peptide levels in children: Comparison in cardiac and non-cardiac diseases. Cardiol Young. 2020;30(4):500-4. https://doi.org/10.1017/ S1047951120000402

PMid:32102709

15. Mehta AV, Goenka S, Chidambaram B, Hamati F. Natural history of isolated ventricular septal defect in the first five years of life. Tenn Med. 2000;93(4):136-8.

PMid:10754804

16. Miyake $T$, Shinohara $T$, Fukuda $T$, Ikeoka M, Takemura $T$. Spontaneous closure of perimembranous ventricular septal defect after school age. Pediatr Int. 2008;50(5):632-25. https:// doi.org/10.1111/j.1442-200X.2008.02642.x

PMid:19261109

17. Cantinotti M, Assanta N, Murzi B, Lopez L. Controversies in the definition and management of insignificant left-to-right shunts. Heart. 2014;100(3):200-5. https://doi.org/10.1136/ heartjnl-2013-304372

PMid:23886608

18. Hart JP, Cabreriza SE, Walsh RF, Printz BF, Blumenthal BF, Park DK, et al. Echocardiographic analysis of ventricular geometry and function during repair of congenital septal defects. Ann Thorac Surg. 2004;77(1):53-60. https://doi.org/10.1016/ S0003-4975(03)01328-6

PMid:14726034

19. Baghdady Y, Kamel Y, Amar W. Myocardial performance index after surgical correction of ventricular septal defects. Arch Med Sci. 2010;6(3):328-35. https://doi.org/10.5114/ aoms.2010.14251

PMid:22371767

20. Mongeon F, Burkhart H, Ammash N, Dearani J, Li Z, Warnes $\mathrm{C}$, et al. Indications and outcomes of surgical closure of ventricular septal defect in adults. JACC Cardiovasc Interv. 2010;3(3):290-7. https://doi.org/10.1016/j.jcin.2009.12.007 PMid:20298987

21. Gabriel HM, Heger M, Innerhofer P, Zehetgruber M, Mudigler G, Wimmer M, et al. Long-term outcome of patients with ventricular septal defect considered not to require surgical closure during childhood. J Am Coll Cardiol. 2002;39(6):1066-71. https://doi. org/10.1016/s0735-1097(02)01706-0 PMid:11897452

22. Pawelec-Mojtalik M, Wojtalik M, Mrówczyński W, Sumarcz R. Closure of perimembranous ventricular septal defect using transcatheter technique versus surgical repair. Kardiol Pol. 2005;63(6):595-602

PMid: 16380857 